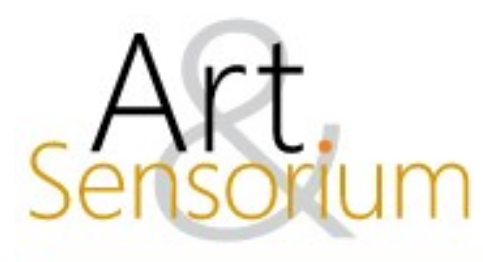

\title{
LADY DIMISTRESCU EM RESIDENT EVIL VILLAGE: A MASSIFICAÇÃO DA CULTURA BDSM ATRAVÉS DOS MEMES
}

\author{
DOI: https://doi.org/10.33871/23580437.2021.8.2.189-204
}

\author{
José Antônio Loures ${ }^{1}$ \\ Caio Túlio Olímpio Pereira da Costa ${ }^{2}$ \\ Dayane Costa Oliveira da Silva ${ }^{3}$
}

\begin{abstract}
Resumo: $O$ artigo versa de forma ensaística sobre uma tríade formulada pelos seguintes pilares teórico-metodológicos: 1) a cultura BDSM e games; 2) a personagem Lady Dimitrescu de Resident Evil: Village, de 2021; e 3) os memes e seu impacto na sociedade pós-moderna sob ótica da Memética. Parte-se do sentido de que a conexão entre essas frontes resulta na massificação e compartilhamento de uma cultura de nicho que parte do underground para o mainstream, tendo um game e uma personagem como força-motriz desse processo. Como metodologia, emprega-se um estudo de caso clássico ao mesmo tempo em que traz os holofotes à uma perspectiva teórico-ensaística de Observação-Participante. Evidencia-se, portanto, uma intimidade vivencial entre consumir a cultura pop pelos games ao mesmo tempo em que se massifica uma cultura de nicho, justificando essa mídia como uma tecnologia da imagem e do imaginário.
\end{abstract}

Palavras-chave: Game Studies; BDSM; Dimitrescu; Memes.

\section{LADY DIMISTRESCU IN RESIDENT EVIL VILLAGE: THE MASSIFICATION OF THE BDSM CULTURE THROUGH MEMES}

\begin{abstract}
The article aims at the theoretical-methodological triad formulated by: 1) the BDSM culture and games; 2) the character Lady Dimitrescu from Resident Evil: Village, of 2021; and 3) memes and their impact on the post-modern society under the Memetics perspective. It starts from the connection between these references resulting on the massification and sharing of a niche culture that leads the underground to mainstream, pointing out a game and a character as driving force of this process. As methodology, it carries out a classic case study as well as highlights a Participation
\end{abstract}

\footnotetext{
${ }^{1}$ Artista multimídia, professor de Histórias em Quadrinhos, e produtor cultural. Doutor em Artes pela Universidade de Brasília (UnB), professor de Artes no Instituto Federal de Educação, Ciência e Tecnologia de São Paulo (IFSP) e Coletivo Interdisciplinar de Pesquisa em Games (CIPEG). Anápolis, Goiás. Lattes: http://lattes.cnpq.br/2089042854569020. ORCID: https://orcid.org/0000-0001-9434-9913 e e-mail: jloures.arte@gmail.com.

${ }^{2}$ Doutorando em Educação Tecnológica pela Universidade Federal de Pernambuco e Membro do Coletivo Interdisciplinar de Pesquisa em Games (CIPEG). Recife, Pernambuco. Lattes: http://lattes.cnpq.br/5202311461970353. ORCID: https://orcid.org/0000-0002-7201-7157 e-mail: caiotuliocosta3@gmail.com.

${ }^{3}$ Graduada em Artes Visuais com habilitação em Artes Plásticas pela Universidade Federal de Goiás (FAV/UFG). Mestre em Comunicação pelo Programa de Pós-Graduação em Comunicação da Universidade Federal de Goiás (PPGCOM/UFG). Doutoranda em Comunicação pelo Programa de Pós-Graduação em Comunicação da Universidade Federal de Goiás (PPGCOM/UFG). Lattes: http://lattes.cnpq.br/5176618561358255. ORCID: https://orcid.org/00000002-0948-3470 e e-mail: dayanecosta91@gmail.com.
} 
Observation. It demonstrates how a way between consuming pop culture throughout games and a massification of a niche culture is able to justify this media as an image and imaginary technology.

Keywords: Game Studies; BDSM; Dimitrescu; Memes.

\section{LADY DIMITRESCU EM RESIDENT EVIL VILLAGE: LA MASIFICACIÓN DE LA CULTURA BDSM A TRAVÉS DE LOS MEMES}

Resumen: El artículo es un ensayo sobre una tríada formulada por los siguientes pilares teóricometodológicos: 1) la cultura BDSM y juegos; 2) el personaje Lady Dimitrescu de Resident Evil: Village, de 2021; y 3) los memes y su impacto en la sociedad posmoderna desde la perspectiva de la Memetica. Se parte de la sensación de que la conexión entre estos frentes resulta en la masificación y el intercambio de una cultura de nicho que va del underground al mainstream, con un juego y un personaje como motor de este proceso. Como metodología, emplea un estudio de caso clásico al tiempo que destaca la perspectiva teórico-ensayística de la Observación-Participante. Por tanto, existe una intimidad vivencial entre consumir la cultura pop a través de los juegos al mismo tiempo que se masifica una cultura de nicho, justificando este medio como una tecnología de imagen e imaginación

Palabras-clave: Game Studies; BDSM; Dimitrescu; Memes.

\section{INTRODUÇÃO}

A franquia de jogos Resident Evil (1996 - 2021) é uma das mais influentes e pioneiras do gênero de horror e sobrevivência e com o seu primeiro título sendo lançado em março de 1996 para o PlayStation. A série de jogos é desenvolvida e publicada pela Capcom, empresa japonesa também conhecida por: Street Fighter (1987 - 2021), Mega-Man (1987 - 2020), Devil May Cry (2001 - 2019) e Monster Hunter (2004 - 2021). Recentemente, a série Resident Evil atingiu a marca de 105 milhões de jogos vendidos (ANDRETTO, 2020) e aparece em 5 posições na lista dos 10 jogos mais vendidos pela Capcom em sua história (LIMA, 2021). Uma marca deveras expressiva, ainda mais por se tratar de jogos com o selo de classificação Mature $+17^{4}$, ou seja, voltados para o público adulto, pois, apresenta sangue e violência, violência intensa e linguagem forte.

Em 2021 foi lançado Resident Evil Village, o oitavo título da série principal com a promessa de encerrar a história de Ethan Winters - o protagonista apresentado no jogo anterior. Nessa nova aventura, Ethan deve sobreviver a uma incessante caçada para salvar a sua filha de lobisomens famintos, vampiras sádicas, bonecas sorrateiras e até um peixe solitário. Contudo, a divulgação do game em seus primeiros teasers e trailers, ainda no ano de 2020, chamou atenção também pela introdução da personagem Lady Dimitrescu, que reverberou em um efeito cascata de memes e de associações de hiperssexualização tangenciais à cultura BDSM e sua ligação com os games em fóruns e comunidades virtuais.

A partir dessa contextualização, o presente artigo discorre de forma ensaística sobre uma tríade formulada entre os seguintes pilares teórico-metodológicos: (1) a cultura BDSM e games; (2) a personagem Lady Dimitrescu de Resident Evil Village; e (3) os memes e seu impacto na sociedade pós-moderna sob ótica da Memética, o estudo formal dos memes (DAWKINS, 1976).

\footnotetext{
${ }^{4}$ Os jogos lançados nos EUA, Canadá e América Latina são regulados pela ESRB (Entertainment Software Rating Board), uma organização que criou um sistema de classificação etária nos videogames. Suas categorias são: Early Childhood (EC), para crianças maiores de 3 anos; Everyone (E), para crianças acima de 6 anos; Everyone 10+ (E10+), que apresenta conteúdo impróprio para crianças menores de 10 anos; Teen $(\mathrm{T})$, que apresenta conteúdo impróprio para menores de 13 anos; Mature +17 (M), com conteúdo impróprio para menores de 17 anos; Adults Only (AO), com conteúdo impróprio para menores de 18 anos; e Rating Pending (RP), que significa que o jogo ainda não foi classificado.
} 
Consequentemente, a conexão entre as três frontes de pesquisa discute um entrelaçar que resulta na massificação e compartilhamento de uma cultura de nicho que parte do underground para o mainstream tendo um game e uma personagem como força-motriz desse processo.

Portanto, como percurso metodológico, emprega-se um estudo de caso clássico (YIN, 2001) da integração entre game, cultura BDSM e memes, ao mesmo tempo em que uma perspectiva teóricoensaística alberga uma Observação-Participante, enquanto ferramental antropológico (TRAUTH; O'CONNOR, 1991), de pesquisadores-jogadores com o caso apresentado e proposto ao longo do artigo.

Partimos, nesse sentido, do pressuposto de que uma intimidade vivencial entre o ofício de consumir a cultura pop contemporânea ofertada pelos games ao mesmo tempo em que se concebe uma massificação de cultura de nicho através de memes é capaz de imergir sujeitos em mobilizações afetivas e retroalimentações entre o que está dentro e fora da tela, justificando, consequentemente, os games como uma tecnologia da imagem e do imaginário (MURRAY, 2003; COSTA, 2020).

\section{BDSM: DOR, PRAZER E PIXELS}

O BDSM é um conjunto diversificado de atividades sexuais relacionadas a disciplina, dominação, submissão, masoquismo e toda uma gama de dinâmica de poder entre dois ou mais parceiros sexuais (NAVARRO-REMESAL; GARCÍA-CATALÁN, 2015). Os praticantes do BDSM se envolvem em um jogo de prazer com dor em uma busca por legitimação, despatologização e descriminação da prática (SILVA; PAIVA; MOURA, 2013). É importante ressaltar, também, que os praticantes do BDSM seguem um rígido sistema de regras relacionado a sanidade, segurança e consensualidade (FACCHINI; MACHADO, 2013).

Nesse sentido, a título de contextualização, ressalta-se que a cultura BDSM se mostra cada vez mais difundida, não se restringindo apenas a um nicho identitário. Um exemplo é o coletivo artístico Nostalgique Cabaret ${ }^{5}$ da cidade de Brasília. Em suas performances, o grupo convida o público para o palco e interagir com os artistas. Durante as apresentações para com o público, diverso, são explorados elementos identitários para além do estereotipo da cor escura, couro e espinhos. Nesse sentido, a internet se mostrou um local prolífero para encontros, debates e uma maneira de socialização das experiências entre os praticantes (SILVA; PAIVA; MOURA, 2013). Nos últimos anos, contudo, o tema se tornou recorrente na cultura pop através da esfera do audiovisual. A título de exemplo trazemos filmes como 50 Tons de Cinza (2015) e 365 Dias (2020).

Contudo, de acordo com Loures (2020), a sexualidade humana se mostra um aspecto inerente também aos jogos digitais, pois, em um ou vários momentos da pré-produção, produção, divulgação e na relação com a comunidade de jogadores, a sexualidade se mostrará presente. E, muitas vezes, indo além dos objetivos dos desenvolvedores e até mesmo impactando o cotidiano daqueles que não se consideram gamers. Assim, o sexo e sexualidade estão cada vez mais visíveis, mais complexos e com mais nuances nos games (WYSOCKI; LAUTERIA, 2016). Em períodos de plataformização da vida esse cenário é ainda mais potencializado (PUAR, 2017).

Nesse contexto, pesquisas teóricas sobre sexualidade, gênero, erotismo e pornografia tem se mostrado um campo em constante expansão nos últimos anos através de um olhar multidisciplinar. Para Sihvonen e Harviainen (2020), a cultura BDSM e os game studies apresentam uma estrutura semelhante desenvolvida por meio de tensões criadas por estruturas de poder baseadas em regras. Por dois anos Raíra Bohrer dos Santos (2016) realizou uma pesquisa etnográfica sobre a relação entre a cultura BDSM e o jogo Second Life, de 1999. Em sua dissertação foi encontrada uma complexa rede

\footnotetext{
${ }^{5}$ Página do coletivo artístico e sensual disponível em: www.instagram.com/nostalgiquecabaretoficial. Acesso em: 20 set. 2021 .
} 
de afeto, micropolítica das relações e construções do corpo para cibersexualidades do BDSM na cultura digital.

O espartano Kratos, protagonista da franquia de games God of War (2005 - 2018), é retratado como uma fantasia masculina: imparável, viril e violento (NAVARRO-REMESAL; GARCÍA-CATALÁN, 2015). Na maioria dos títulos, Kratos era colocado no papel de dominador, mas ao encontrar Afrodite (God of War 3, 2010) a situação se inverte. Há uma cena que o prazer de Kratos não é o objetivo, e sim o orgasmo da deusa do amor. Para Navarro-Remesal e García-Catalán (2015) a cena se assemelha levemente às dinâmicas encontradas no BDSM. Caso o jogador não acerte os comandos durante a cena sexual com Afrodite, a mesma surge para humilhar a performance de Kratos: "Sou muita mulher para você, Kratos?”. Inclusive, na página Rule 34 Data Base (rule34.xxx) é possível encontrar fanarts que colocam Kratos e outros personagens considerados "machos alfa" no papel de submissos, amarrados e à espera de seus dominadores: o público.

Uma outra característica surge quando relacionamos os games com BDSM, o humor. Um exemplo disso é o do game de exploração e aventura Deathtrap Dungeon (1998), onde o jogador escolhe entre dois personagens: um guerreiro com uma armadura completa ou uma guerreira com nenhuma proteção e vestindo um fio dental (bikini armor). Em sua campanha publicitária o visual da personagem foi reaproveitado. Temos uma modelo em trajes fetichistas com um chicote em punho, algo que bebe das fontes da cultura BDSM, em frente a um homem acorrentado tendo em vista uma televisão. A frase em destaque, "Há somente uma coisa mais torturante que jogar Deathtrap Dungeon. Não o jogar", deixa claro as intenções da campanha de relacionar dor com prazer aos jogos digitais. Historicamente a publicidade de videogames utiliza do apelo sexual em suas campanhas, e ainda é possível encontrar imagens que usam os corpos das personagens, jogadoras e modelos para atrair a atenção do público masculino (LOURES, 2018).

Outro exemplo foi o fenômeno da personagem Bowsette, que inundou as redes sociais com conteúdo adulto através de memes ${ }^{6}$. Esta, por sua vez, não foi planejada pela Nintendo - detentora da propriedade intelectual dos jogos da franquia Super Mario Bros. (1985 - 2021) e através de uma intrínseca e criativa rede colaborativa logo estava presente em jogos oficiais através de modificações, filmes e animações pornográficas, tornando-se um dos termos mais buscados no Google. Na página dedicada a conteúdos pornográficos PornHub foram realizadas 34,687,477 pesquisas com pico de crescimento em $776 \%$ em 30 de setembro no ano de 2018. No mesmo ano Bowsette foi a personagem de videogame mais procurada no PornHub e com 30 milhões de buscas acima do segundo colocado, a personagem Brigitte de Overwatch (2016).

Assim, a cultura BDSM se mostra presente por meio de várias dinâmicas quando se trata de games. A personagem principal desse artigo, Lady Dmitrescu, não está alheia à essas caraterísticas. Contudo, para uma compressão mais expressiva da articulação apresentada pelo artigo, faz-se necessário responder à pergunta: Quem é Alcina Dimitrescu?

\section{ALCINA DIMITRESCU: A MULHER ALTA QUE QUEBROU A INTERNET}

Na narrativa do game Resident Evil Village, o oitado título canônico da linha principal de jogos da franquia japonesa de horror e sobrevivência lançado em 2021, Lady Alcina Dimitrescu é a matriarca

\footnotetext{
${ }^{6}$ Em 19 de setembro de 2018, um usuário do Twitter identificado como Ayyk92 publicou uma tirinha. Na narrativa o herói Mario e o vilão Bowser são dispensados por Peach, e em uma reviravolta inesperada o vilão utiliza o item mágico Super Crown, ganhando sua versão feminina, um híbrido entre dinossauro e o corpo humano de Peach com adereços referenciando a cultura BDSM (LOURES, 2021).
} 
da tradicional família Dimitrescu, e herdeira do castelo de mesmo sobrenome situado em um fíctício Leste Europeu?

Durante a década de 1950, Dimitrescu recebeu um Cadou - um ancestral parasita mutante, de Mãe Miranda, o que causou diversas mutações em seu corpo. Um dos efeitos dessa relação simbiótica foi a capacidade sobre-humana de regeneração, o que permitiu Dimistrescu conservar-se com 44 anos permanentemente. Devido a essa capacidade regenerativa o corpo da personagem não parou de crescer e alcançou os 2,9 metros de altura e estimados 270 quilos durante os principais acontecimentos de Resident Evil: Village.

No conteúdo extra desbloqueado ao terminar o game é possível encontrar uma arte conceitual da personagem e suas vestimentas, onde inclusive podemos saber a cor da roupa íntima de Dimitrescu (Figura 1). De acordo com os desenvolvedores (KIM, 2021), o visual da personagem foi inspirado por três figuras femininas: Hachishakusama, lenda japonesa de uma mulher "demônio" alta vestida de branco que rapta crianças; Elizabeth Báthory, condessa húngara do século 16 a qual se atribui uma série de assassinatos em busca de imortalidade e beleza; Morticia Addams, a matriarca da família Addams, uma personagem que ganhou popularidade quando interpretada pela atriz Anjelica Huston em um filme lançado em 1991.

Devido uma doença hereditária, Alcina Dimitrescu é obrigada a consumir carne e sangue humanos para manter a regeneração de seu corpo. Além da sua enorme estatura, a personagem possui unhas capazes de se alongar, retrair, e cortar com facilidade tecidos orgânicos e estruturas de madeira, metal e pedra. Como se Dimitrescu não fosse uma ameaça suficiente para o jogador enquanto antagonista, ainda coabitam na narrativa digital suas três filhas: Daniela, Bela e Cassandra - Criaturas insectoides nascidas de ovos de Cadou. Suas filhas simulam a aparência de jovens e belas mulheres com tendências sádicas à tortura e assassinato, mas na verdade seus corpos são formados por uma nuvem de insetos.

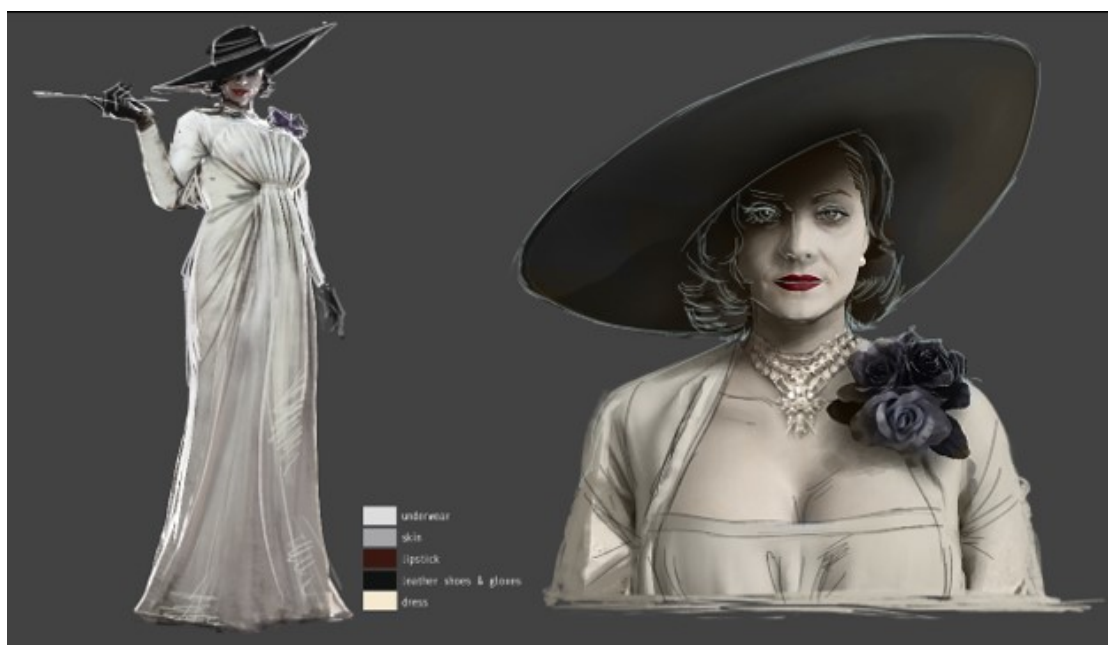

Figura 1 - Arte conceitual de Lady Dimitrescu. Fonte: Extras de Resident Evil: Village.

No início de Resident Evil: Village é mostrada uma disputa por quem ficará responsável por castigar e executar Ethan Winters, o protagonista, recém capturado. As filhas de Dimitrescu querem se divertir com o corpo e Karl Heisenberg, um outro Lorde, insinua que será de uma forma sexual como um boneco a ser usado e dominado. Depois, o protagonista é outra vez capturado no castelo Dimitrescu por Daniela, Bela e Cassandra. As antagonistas se divertem em causar dor, rasgar e perfurar o corpo de Ethan Winters, e durante a tortura as mesmas expressam prazer com a prática. Uma das filhas diz:

\footnotetext{
${ }^{7}$ Nesse ponto do artigo salientamos o aviso de que por se tratarem de elementos narrativos e visuais é imprescindível a presença de spoilers sobre a história de RE:VIII e, respectivamente, seus personagens.
} 
“faz muito tempo que não amarro um homem, deixa eu amarrar você?” Uma referência ao fetiche do shibari - tradicional técnica erótica japonesa que consiste em amarrar ou ser amarrado com cordas. Na versão localizada português do Brasil as vampira se referem aos humanos como "bicho homem".

A decoração do castelo Dimitrescu é composta por locais de tortura com referências medievais: cadeiras com espinhos, jaulas, e cintos de castidade. Durante as andanças pelo castelo, o jogador descobre que Dimitrescu é responsável por torturar e assassinar centenas de empregadas - somente mulheres eram aceitas paro o trabalho. A partir desses assassinatos o sangue das vítimas é usado como matéria prima para o vinho Sanguis Virginis (latim para "Sangue de Donzela"). Ao explorar o castelo, o jogador se colocada no papel de voyeur ao observar a proprietária em diversos momentos sem ser notado. Em um momento, inclusive assiste sorrateiramente Dimitrescu durante uma tensa conversa com Mãe Miranda por telefone que resulta em uma escrivaninha pesada sendo arremessada facilmente. Contudo, o ângulo da câmera do jogo se dedica a destacar o corpo e as enormes nádegas da personagem.

Apesar de seu tamanho avantajado, longas garras, e falas ameaçadoras, o jogador consegue facilmente fugir e evitar ser encontrado por Dimitrescu, perpetuando por boa parte da narrativa digital uma dinâmica de caça entre "gato e rato". Em determinado momento, Ethan Winters encontra uma faca cerimonial ritualística capaz de interromper a regeneração da vilã. Assim, ao ser golpeada a personagem se transforma em uma monstruosa versão quimérica de um dragão. A batalha final contra Dimitrescu acontece no alto de uma torre, mas pode ser inclusive considerada anticlimática perante as expectativas criadas ao longo da campanha publicitária, pois é resolvida brevemente (COOPER, 2021). Em nossa experiencia foram 4 horas de jogo (de um total de 20 horas) desde o primeiro encontro com Lady Alcina Dimitrescu até a venda de seu corpo cristalizado no mercador. É importante dizer que cada jogador terá uma experiência completamente diferente de acordo com a dificuldade escolhida, e tempo necessário para se resolver os quebra-cabeças e enigmas.

Dimitrescu foi apresentada no terceiro trailer de Resident Evil: Village, e sua presença pode ser notada através dos números das diversas reações nas redes sociais. O primeiro trailer do jogo, postado no canal oficial da franquia no YouTube, teve 1 milhão e 200 mil visualizações e 40 mil likes. Enquanto isso, o segundo alcançou 700 mil visualizações e 20 mil likes. Já o terceiro, lançado em 22 de janeiro de 2021, alcançou as 5,5 milhões de visualizações e conta com 137 mil likes ${ }^{8}$. A diferença entre eles? A participação ativa de Alcina Dimitrescu no terceiro trailer do jogo. Com a utilização do Google Trends - ferramenta do Google que mostra os mais populares termos buscados em um determinado momento, podemos ver a popularidade da personagem sendo o segundo termo mais buscado relacionado Resident Evil:Village, perdendo apenas para as buscas sobre o título do jogo, mas superando as buscas sobre Ethan Winters - protagonista de Village e do título anterior (Resident Evil 7), e Chris Redfield - icônico personagem da franquia em títulos anteriores (Figura 2):

\footnotetext{
${ }^{8} \mathrm{O}$ trailer pode ser acessado em: https://www.youtube.com/watch?v=btFclZUXpzA. Acesso em: 20 set. 2021.
} 


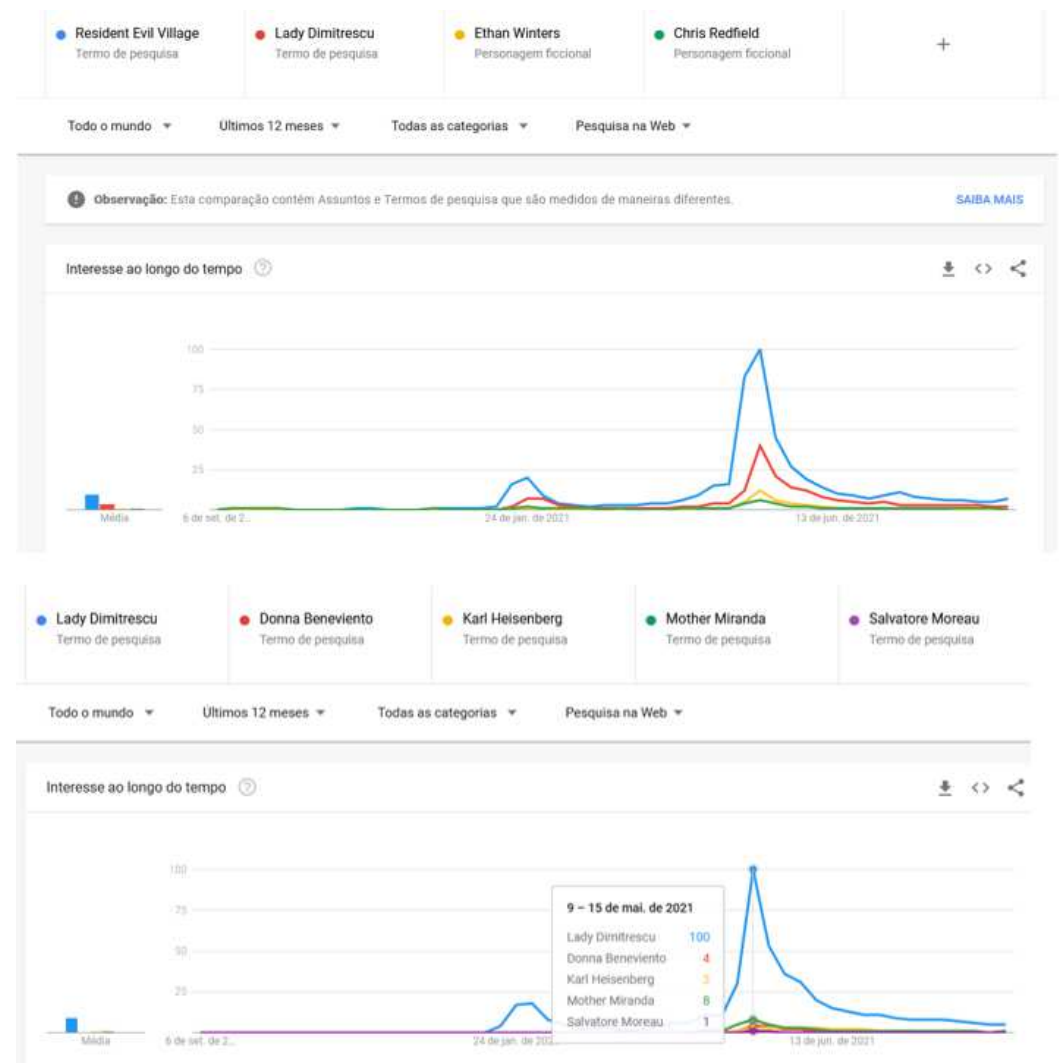

Figura 2 - Popularidade por termos buscados. Fonte: Google Trends.

Resident Evil: Village apresenta quatro Lordes que servem à enigmática e idolatrada Mãe Miranda: Lady Dimitrescu - uma vampira sedenta por sangue; Donna Beneviento - uma misteriosa mulher acompanhada pela boneca viva Angie; Karl Heisenberg - um gênio da engenharia com poderes eletromagnéticos; e Salvatore Moreau - um cientista solitário e deformado amante de queijos. Nem mesmo Mãe Miranda e os outros lordes foram capazes de se aproximar da popularidade de Dimitrescu.

Os comentários mais relevantes presentes no terceiro trailer são em maioria de jogadores que definitivamente não se mostram assustados pela presença de Dimitrescu. Muito pelo contrário, são diversos relatos de pessoas excitadas com o corpo e aparência da personagem. É importante perceber que no período de lançamento do terceiro trailer a personagem quase se tornou o termo mais buscado na internet quando se tratava de Resident Evil:Village. Além disso, como a popularidade da personagem sempre superou e ainda supera os demais personagens principais do jogo. Pelos motivos apresentados acima, é notável a repercussão e o impacto de Lady Dimitrescu na série Resident Evil, e na cultura digital. Mesmo com sua participação de apenas algumas horas, a personagem foi capaz de cativar e atrair a comunidade de jogadores. Nesse contexto, o encontro entre Alcina Dimitrescu e os memes se mostrou fértil para a produção e compartilhamento de imagens sobre a personagem, e principalmente as emoções despertadas no público devido ao seu enorme corpo.

\section{MEMES: REPRODUTIBILIDADE E INFECÇÃO NA CULTURA DIGITAL}

Em 1976 o escritor e biólogo Richard Dawkins desenvolveu o conceito de "meme". De acordo com o autor (1976), o meme é uma fração de um determinado conhecimento que pode ser replicado através da imitação. Os memes podem ser qualquer produção intelectual humana, que se propaga de cérebro em cérebro sofrendo mutações nesse processo (ARISTIMUÑO, 2014). Assim, é uma ideia aberta e a 
informação contida na mensagem pode ser repassada de pessoa para pessoa em diversos níveis e formatos (VIEIRA; GOMES, 2017).

$\mathrm{Na}$ era digital o meme ressurgiu com novos significados e impactos na cultura, produção e compartilhamento de informação nas Redes Sociais. Para Roy Ascott (2003) - artista e pesquisador, a internet está produzindo uma "consciência planetária" decorrente da fusão de todos os usuários presentes no ciberespaço (MACHADO, 2007). Aristimuño (2014) corrobora com esse pensamento ao colocar que o meme é uma entidade que se propaga em escala global nas mídias sociais independentemente do seu conteúdo. Para Veira e Gomes (2017, p. 1140), é na internet que

[...] os memes ganharam outros aspectos, não só textos, mas também imagens e alguns são até vídeos ou animações (gifs) que abusam geralmente do humor para obter a fecundidade necessária para sobreviver mais tempo e atingir longevidades cada vez maiores dentro do ciberespaço.

Nesse contexto, os memes são construtores de narrativas contemporâneas (ARISTIMUÑO, 2014). Por esse motivo, é importante uma abordagem multidisciplinar para investigá-los em um cenário digital (LIMA; CASTRO, 2016). E a multidisciplinaridade é uma característica fundamental no processo criativo e de pesquisa desenvolvido na escrita desse artigo.

Assim, os conteúdos sobre games encontraram nos memes uma alternativa intensa, prolifera (mas nem sempre ética) de se propagarem através das mídias sociais. Nesse sentido, podemos separar os memes em três categorias distintas (TREVISAN; PRÁ; GOETHEL, 2016): 1) o meme que utiliza algum personagem já existente, como por exemplo personagens de filmes, games, séries e livros; 2) o meme que se apropria do discurso político com um objetivo político, como por exemplo a Barbie Fascista9; e 3) o meme que se apropria de obras e criações artísticas e culturais com o objetivo de subversão e releitura, como por exemplo o Newmememuseum ${ }^{10}$. De acordo com o recorte do artigo a primeira categoria foi a escolhida para o desenvolvido das ideias e problematização acerca do tema proposto: Lady Dimistrecu.

\title{
5. A CONVERGÊNCIA ENTRE FETICHE, PUBLICIDADE E MEMES
}

Em recente entrevista para o portal IGN, Tomonori Takano - diretor de arte de Resident Evil: Village revelou que não entende a fissura da comunidade perante Dimitrescu:

\begin{abstract}
Nos primeiros estágios de planejamento, decidimos usar o tema de [um] castelo e vampiros. No entanto, não queríamos ficar restritos pela forma como os vampiros acabaram retratados em várias formas de entretenimento popular. A primeira peça de arte conceitual que desenhei para Resident Evil Village foi a cena no trailer em que Lady Dimitrescu se abaixa para passar pela porta. [...]. Acredito, no entanto, que ninguém de nossa equipe poderia prever o quão maravilhados ficariam os fãs ao descobrirem Lady Dimitrescu. Pessoalmente, eu fiquei estarrecido com alguns comentários do tipo 'quero ser perseguido por ela'. "Assim, como qualquer bom personagem que deixa as pessoas com tesão, [Lady Dimitrescu é] uma combinação de vários fetiches de nicho diferentes. Obviamente, ela é uma vampira, e a fantasia de ser devorada ou consumida por um vampiro é clássica neste ponto. Eles (vampiros em geral) desejam algo tabu sobre você - seu sangue, sua força vital - e têm que machucálo para consegui-lo, mas o êxtase de ter seu sangue drenado torna-se sempre enquadrado como sexo (CARVALHO, 2021, online).
\end{abstract}

\footnotetext{
${ }^{9} \mathrm{O}$ Instagram pode ser acessado em: https://www.instagram.com/barbiefascista. Acesso em: 18 set. 2021.

${ }^{10} \mathrm{O}$ Instagram pode ser acessado em: https://www.instagram.com/newmemeseum. Acesso em: 20 ago. 2021.
} 
É interessante perceber que Dimitrescu foi planejada para seduzir o jogador por ser uma vampira, mas de acordo com Takano a paixão da comunidade pela estatura da personagem não estava nos planos. O que foi posteriormente usado pela Capcom na campanha publicitária do jogo, por exemplo temos a personagem em tamanho real estampando tolhas e onibus (YIN-POOLE, 2021) (Figura 3):

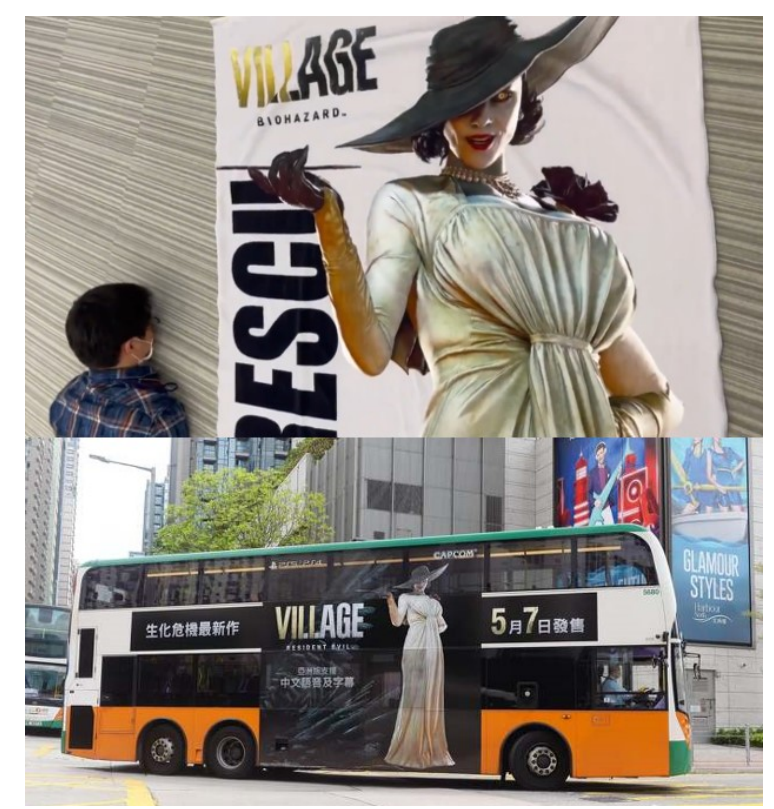

Figura 3 - Campanha publicitária de Resident Evil: Village no Japão. Fonte: Eurogamer.

No Brasil, a Warner, publicadora oficial de Resident Evil: Village, também se aproveitou do corpo de Dimitrescu em sua campanha publicitária (Figura 4):

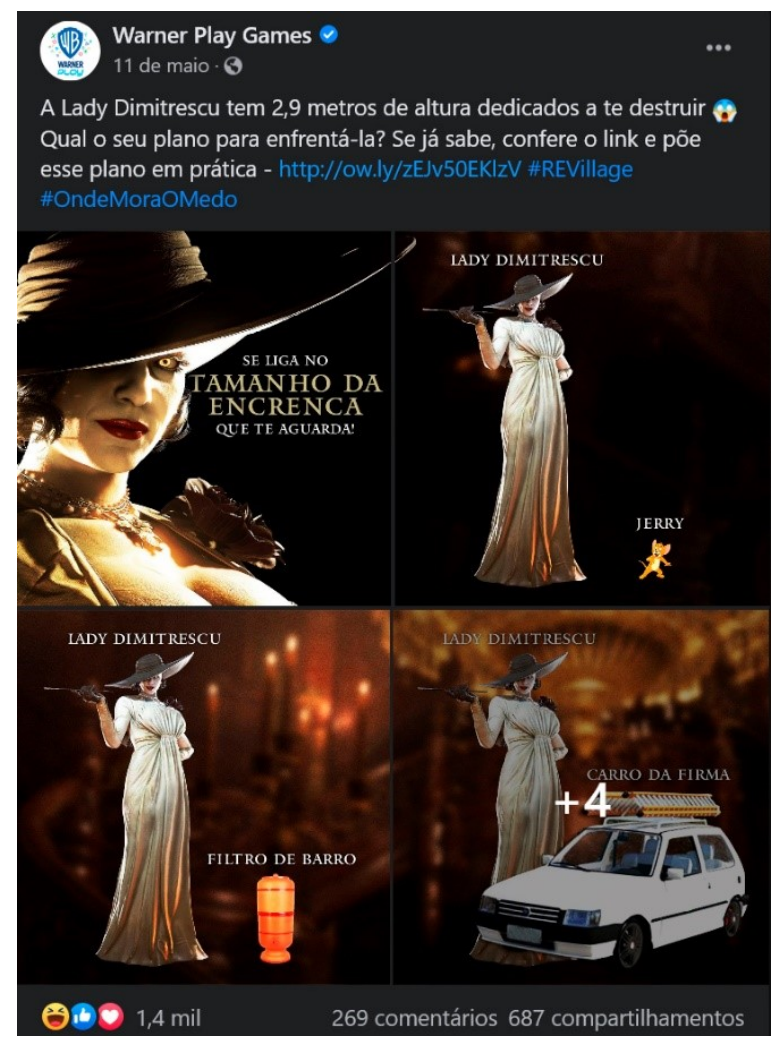

Figura 4 - Campanha publicitária da Warner no Brasil. Fonte: Facebook. 
A personagem tem o tamanho comparado com objetos inanimados como o tradicional filtro de barro brasileiro, um carro e o rato Jerry. Os comentários são exponencialmente de jogadores atraídos pelo corpo de Dimitrescu e seu potencial erótico.

A macrofilia é o desejo, admiração e fantasia sexual envolvendo gigantes. Os macrofilos podem ser do gênero masculino e feminino, heterossexuais, bissexuais, homossexuais e outros espectros da sexualidade humana. Contudo, a maioria dos fascinados por esse fetiche são homens heterossexuais fascinados por mulheres gigantes (WEISMAN, 2014). A sexóloga Tâmara Dias relaciona a macrofilia com uma busca cultural por dominância e proteção (OLIVEIRA, 2020). Já de acordo com o terapeuta sexual Todd Anderson (WONG, 2021, online, tradução nossa):

Embora nem sempre seja o caso, o homem/micro pode desfrutar do sentimento de submissão para outro mais poderoso. Em nossa cultura há uma associação de 'grande' com 'poderoso'. A mulher/macro representa um relacionamento social relativamente aceitável que é 'outro poderoso' com quem o macho/micro pode explorar necessidades, desejos, conflitos e temas relacionais. Embora esses temas sejam frequentemente representados no "reino" sexual, eles não precisam ser inerentemente sexuais. No entanto, a sexualidade, devido à interpenetração e contato concretos dos corpos físicos, presta-se à expressão concreta de necessidades mais abstratas. Anseios, necessidades, desejos e conflitos podem ser desempenhados com segurança no contexto de um relacionamento com um 'outro' que também está disposto a se envolver de tal maneira.

Os fetiches (BDSM e macrofilia) envolvendo Dimitrescu foram potencializados pela mídia e redes sociais. Por exemplo, temos as manchetes “We've Done The Math: Letting Lady Dimitrescu Stand On Your Chest Will Definitely Kill You" e "Resident Evil Village: YouTuber Explains What Would Happen if Lady Dimitrescu Actually Stood on You". Ambas as matérias são focadas em colocar o jogador no papel de uma cadeira, aquela que vemos Dimitrescu sentada ao conversar por telefone com Mãe Miranda (Figura 5):
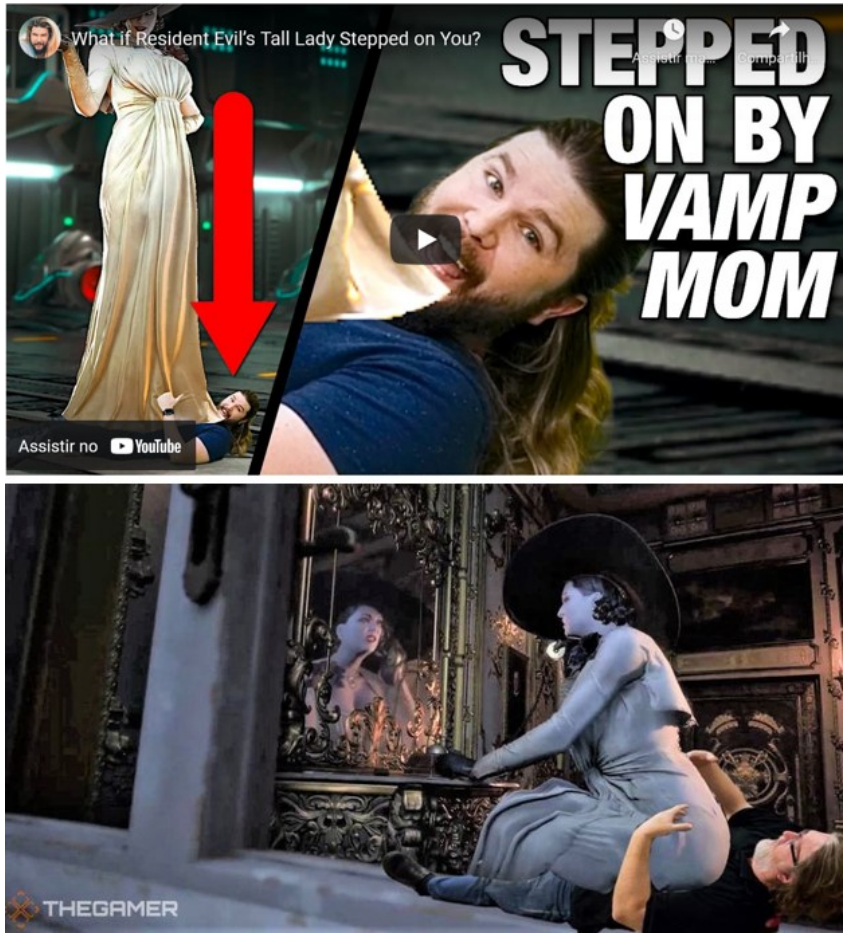

Figura 5 - Dimitrescu sentando nos jogadores. Fonte: YouTube/TheGamer. 
Lady Dimitrescu foi utilizada em campanhas publicitárias e em matérias sensacionalistas consideradas clickbait, a técnica utilizada por páginas sensacionalistas para atrair o clique do usuário. Dessa maneira, podemos entender que a objetificação do corpo da personagem atende as necessidades do sistema capitalista. O corpo de Alcina é um produto a ser comercializado de maneira literal para atrair a atenção dos consumidores.

No Brasil os memes da personagem foram relacionados com especificidades da nossa cultura e o seu principal meio de compartilhamento foram as Redes Sociais: Instagram, Twitter e Facebook. Em uma das imagens compartilhadas pelo perfil "bad.memes.vibes ${ }^{11 "}$ temos uma cosplayer pisando no jogador e uma frase referenciando a venda de pacotes de fotos e vídeos eróticos através do PIX ${ }^{12}$ (Figura 6):

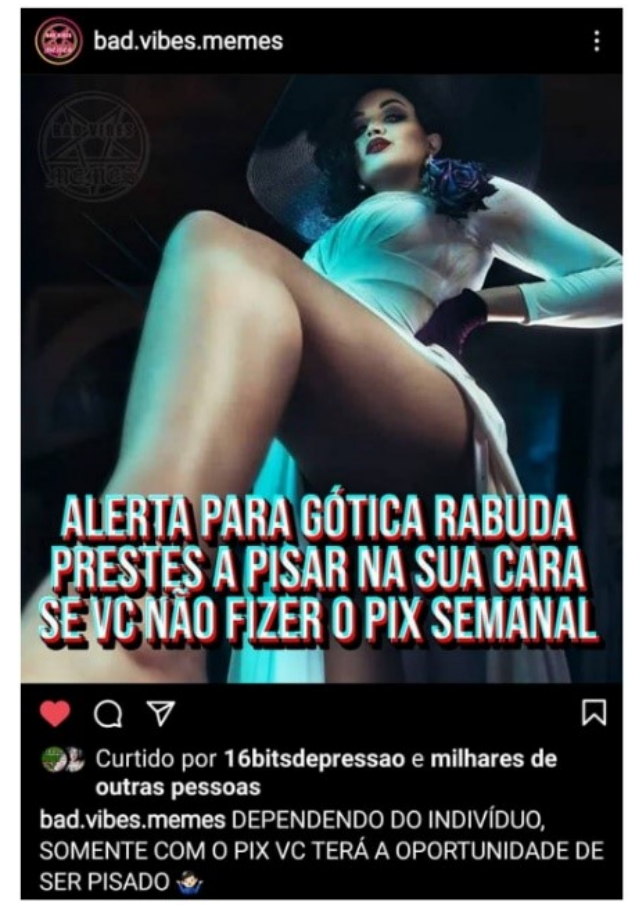

Figura 6 - Dimitrescu subjugando o público. Fonte: Instagram.

A imagem coloca o jogador em um papel de submissão perante a cosplayer, ressaltando os aspectos da cultura BDSM com serviços de conteúdo adulto. No Facebook a página "Capas Alternativas de

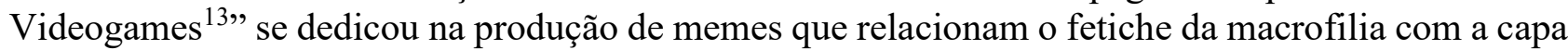
de Resident Evil: Village (Figura 7):

\footnotetext{
${ }^{11}$ A página conta com 510 mil seguidores e pode ser acessada em: https://www.instagram.com/bad.vibes.memes. Acesso em 09 set. 2021.

${ }^{12}$ Meio de pagamento eletrônico instantâneo utilizado através de aplicativos e lançado em outubro de 2020 no Brasil.

${ }^{13}$ A página Capas Alternativas de Videogames conta com 45 mil seguidores no Facebook e pode ser acessada em: https://www.facebook.com/capasalternativasdevideogames/. Acesso em: 15 set. 2021.
} 

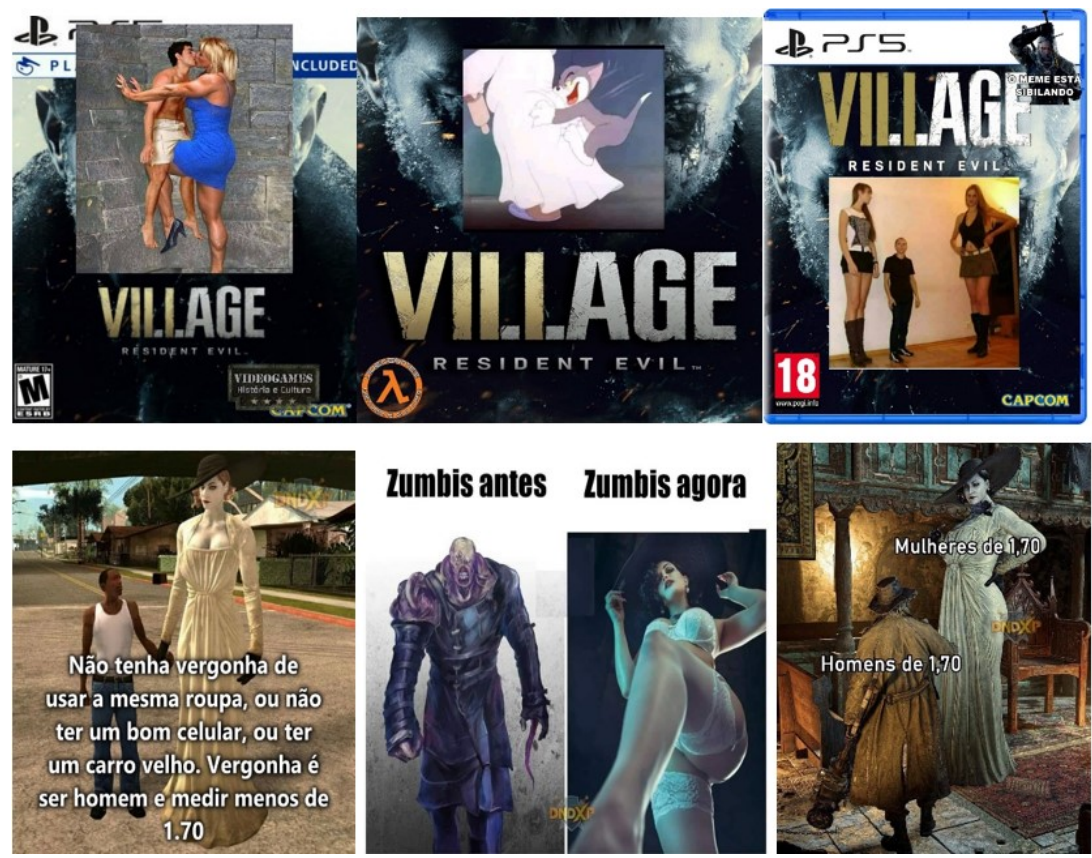

Figura 7 - Videogames" e "Dormir não dá XP - RPG Brasil".- Memes sobre Dimitrescu e Macrofilia. Fonte: Facebook ("Capas Alternativas de

Nas imagens vemos homens de pequena estatura (e até mesmo o Tom, de Tom e Jerry (1940) atraídos e subjugados por grandes mulheres. Por esses memes é possível afirmar que a principal visualidade referenciada ao jogo é a mulher alta, ou seja, Lady Alcina Dimitrescu. A página "Dormir não dá XP - RPG Brasil ${ }^{14 » ~ t a m b e ́ m ~ f o c a d a ~ e m ~ m e m e s ~ d e ~ v i d e o g a m e s ~ t a m b e ́ m ~ p r o d u z i u ~ v a ́ r i a s ~ i m a g e n s ~ s o b r e ~ a ~}$ personagem.

A página "EvilHazard ${ }^{15 " ~ f o c a d a ~ e m ~ i n f o r m a c ̧ o ̃ e s ~ s o b r e ~ a ~ s e ́ r i e ~ R e s i d e n t ~ E v i l ~ t a m b e ́ m ~ p u b l i c o u ~ v a ́ r i o s ~}$ memes envolvendo Dimitrescu (Figura 8). A maioria dos comentários encontrados nessas imagens destoam completamente da intenção dos desenvolvedores de assustar os jogadores, no caso de Dimitrescu existe uma intencionalidade de encontrá-la, e até mesmo ser o principal motivo de se adquirir uma cópia de Resident Evil: Village.

\footnotetext{
${ }^{14}$ A página Dormir não dá XP - RPG Brasil conta com 457 mil seguidores no Facebook e pode ser acessada em: https://www.facebook.com/Dormirnaodaxprpgbrasil/. Acesso em: 20 set. 2021.

${ }^{15}$ Com 254 mil seguidores no Facebook, pode ser acessada em: www.facebook.com/evilhazard/. Acesso em: 15 set. 2021.
} 

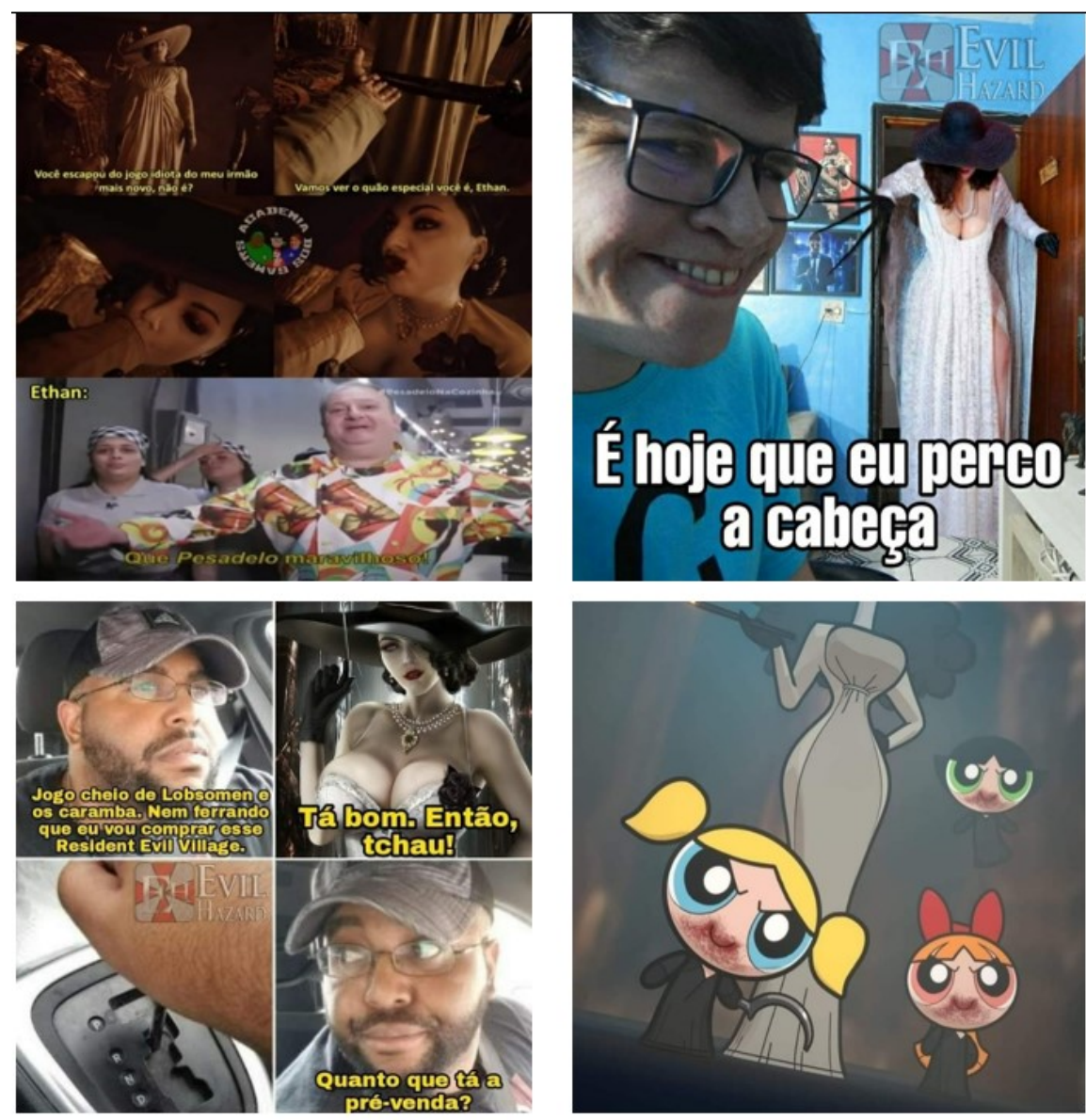

Figura 8 - Memes brasileiros diversos sobre Dimitrescu. Fonte: Facebook (“Evil Hazard”).

Essa euforia pela personagem transbordou para além dos meios digitais, e começou a influenciar aspectos do cotidiano. Por exemplo, uma suicide girl ${ }^{16}$ brasileira se aproveitou da popularidade de Dimitrescu e suas filhas para vender pacotes de fotos e vídeos eróticos de cosplayer. É comum encontrar fotos de cosplayers sensuais de Dimitrescu e suas filhas em diversas páginas na internet, inclusive para aquelas que não abordam o universo dos jogos digitais. Assim como também encontramos produções pornográficas envolvendo a personagem (Figura 9).

De acordo com Jean Baudrillard (1991), a humanidade produz imagens consideradas mais que reais quando o referencial é perdido. Isso é potencializado pela constante evolução tecnológica, e atualmente os videogames são um dos principais produtores e veículos dessas imagens (LOURES; COSTA, 2020). Lady Dimitrescu alcançou popularidade ao subjugar o jogador enquanto o seu próprio corpo digital é sexualizado e explorado por jornais, páginas de memes e comunidade de jogadores em um fetiche sexual que mescla o real com o digital.

Os memes são efêmeros, pois diariamente são produzidas e compartilhadas milhões de imagens para atender a cultura do hype - meme utilizado para expressar diversos níveis de expectativas e empolgação com determinado conteúdo (BOAVENTURA, 2016). Resident Evil: Village foi lançado em 7 de maio de 2021, e após esse período a empolgação e consequentemente a quantidade de memes sobre Lady Dimitrescu foram se tornando cada vez mais escassos, até o momento que foram substituídos por novos assuntos e notícias envolvendo a cultura do hype.

\footnotetext{
${ }^{16}$ Modelo alternativa de uma página de assinatura com o mesmo nome.
} 


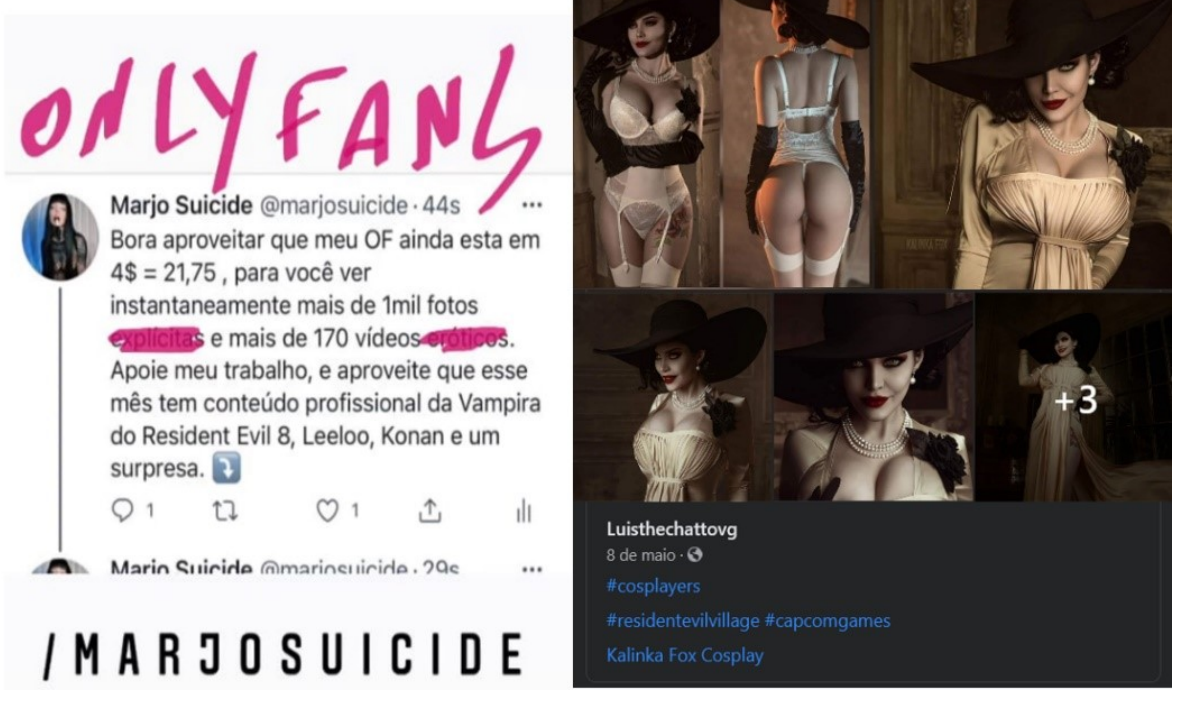

Figura 9 - Cosplayers eróticas de Lady Dimitrescu. Fonte: Twitter e Facebook (“@marjosuicide” e "Luisthechattovg", respectivamente).

Existem algumas iniciativas para tentar preservar os memes, como a página knowyourmeme ${ }^{17}$ que age tanto de catálogo, termômetro e museu para os memes. Já no Brasil existe o Museu de Memes ${ }^{18}$, um projeto da Universidade Federal Fluminense que conta a participação e doação de memes pela comunidade na construção de sua coleção. Assim, a curta, mas intensa passagem de Lady Alcina Dimitrescu pela internet e redes sociais pode ser mapeada para compreender esse fenômeno.

\section{CONSIDERAÇÕES FINAIS}

A franquia Resident Evil, em teoria, tem abordado em seus títulos um vírus capaz de contaminar os seres humanos os transformando em armas biológicas usadas por grupos terroristas e governos corruptos. Contudo, nos últimos games a série abordou as relações familiares e emoções como egoísmo, amizade, medo, arrogância e amor. Nesse contexto, os memes sobre Resident Evil: Village se manifestam também como um vírus sendo replicado em ritmo descontrolado até que todos estejam vacinados e imunizados, ou seja, cansados e exauridos por consumir o mesmo conteúdo "hypado". Os memes surgem e se espalham exponencialmente, assim como também no mesmo ritmo são substituídos e caem no esquecimento.

Nesse artigo, os memes sobre Dimitrescu brotaram de maneira cômica e despretensiosa na internet e redes sociais. Contudo, existem camadas profundas que abordam a sexualidade humana e consequentemente seus desejos e fetiches. Lady Alcina Dimitrescu foi capaz de furar a bolha da cultura BDSM, e alcançou um público diverso em diferentes áreas e ambiências na cultura digital. Os memes envolvendo Dimitrescu são espelhos que refletem aspectos da sexualidade humana, talvez por isso a comunidade de jogadores e não jogadores tenha aceitado tão bem a visualidade da personagem e reverberado seus desejos e curiosidades através de memes e por buscas no Google e em sites pornográficos.

Acredita-se, portanto, que a relação emotiva despertada pelos personagens de videogames se torne cada vez mais frequente e com consequências em nosso cotidiano, estreitando cada vez mais os laços entre o real e virtual. Esses impactos são mais visíveis em gerações que nasceram, cresceram e estão

\footnotetext{
${ }^{17}$ A página pode ser acessada em: https://knowyourmeme.com/memes/lady-dimitrescu. Acesso em: 05 set. 2021.

${ }^{18}$ A página pode ser acessada em: https://museudememes.com.br/. Acesso em: 07 set. 2021.
} 
inseridas no universo dos jogos digitais. Nesse sentido, através da plataformização do desejo sexual, do erotismo disfarçado de humor e pela experiência de jogar e imaginar, os games se tornam, através de memes, a causa e resultado de uma massificação de cultura de nicho que através da cultura pop fura bolhas e assume esferas que não eram de seu cotidiano regular. Por fim, fazemos a seguinte pergunta: Quem será a próxima Dimitrescu?

\section{REFERÊNCIAS}

ANDRETTO, R. Franquia Resident Evil atinge 105 milhões com crescimento de vendas de jogos com a RE Engine. REVIL - Notícias, 2020.

ARISTIMUÑO, F. O meme como expressão popular no ensino de arte. Art\&, vol. 15, 2014.

ASCOTT, R. Quando a Onça se Deita com a Ovelha: a Arte com Mídias Úmidas e a Cultura PósBiológica. São Paulo: Unesp, 2003.

BAUDRILLARD, J. Simulacros e Simulação. Lisboa: Relógio D’Água, 1991.

BOAVENTURA, J. P. B. O jornalismo de games e a cultura do Hype como estratégia de venda. $S B C$ - Proceedings of SBGames 2016. São Paulo, 2016.

CARVAlHO, F. Resident Evil Village: Dev não entende "fissura" dos fãs por Lady Dimitrescu. Combo Infinito - Games, 2021.

COOPER, D. Resident Evil Village Drops the Ball with Lady Dimitrescu. GameRant, 2021.

COSTA, C. T. O. P. A experiência sensivel na imersão em jogos de videogame. Dissertação (Mestrado em Comunicação). Centro de Artes e Comunicação - UFPE, 2020.

DAWKINS, R. The selfish gene. Oxford University Press, 1976.

FACCHINI, R.; MACHADO, S. Do sadomasoquismo erótico ao BDSM. Anais do Fazendo Gênero $X$, Florianópolis, 2013.

KIM, M. How capcom designed Resident Evil Village's Lady Dimitrescu, and why she's so big online. IGN - Resident Evil 8, 2021.

LIMA, D. Resident Evil e mais: Capcom atualiza lista de mais vendidos. The Enemy - News, 2021.

LIMA, G.; CASTRO, L. Meme digital. Contextos Linguísticos, vol. 15, 2016.

LOURES, J. A pornografia hiper-real dos videogames: a simulação do êxtase. DATJournal, vol. 6, n. 1,2021 .

LOURES, J. Do humano aos pixels: o apelo sexual nas propagandas de videogames. Panorama, vol. 8, n. 1, 2018.

LOURES, J. Homo Sex Ludens: a sexualidade nos videogames. Tese (Doutorado em Artes) - Instituto de Artes - UnB, 2020.

LOURES, J.; COSTA, C. T. O. P. O Eros em uma sociedade cansada: uma busca narcisista pelo outro através dos videogames. Art \& Sensorium, vol. 7, n. 2, 2020.

MACHADO, A. Arte e mídia. Rio de Janeiro: Zahar, 2007.

MURRAY, J. H. Hamlet no holodeck: o futuro da narrativa no ciberespaço. Itaú Cultural, 2003.

NAVARRO-REMESAL, V.; GARCÍA-CATALÁN, S. Let's play master and servant: BDSM and directed freedom in game design. New York: Bloomsbury, 2015. 
OLIVEIRA, T. Poder e dominação. Metrópoles: Pouca Vergonha, 2020.

PUAR, J. The right to maim: debility, capacity, disability. Duke University Press, 2017.

SANTOS, R. B. Castelos de Pixels: relacionamentos BDSM no mundo digital virtual 3D Second Life. Dissertação (Mestrado em Sociologia). Centro de Ciências Sociais e Humanas - UFSM, 2016.

SIHVONEN, T.; HARVIAINEN, J. "My Games are... Unconventional". Sage Journals, 2020.

SILVA, M. J.; PAIVA, A. C. S.; MOURA, A. A. Da submissão à feminização masculina: subversões de gênero no BDSM. In: Seminário Internacional Desfazendo Gênero I, 2013. Anais..., Natal: UFRN, 2013.

TRAUTH, E. M; O'CONNOR, B. A study of the interaction between information technology and society. Amsterdam: North-Holland, 1991.

TREVISAN, M.; PRÁ, E.; GOETHEL, M. Meme. Observatório, vol. 2, n. 1, 2016.

VIEIRA, T.; GOMES, N. Os memes criados pelos gamers. Philologus, vol. 23, n. 67, 2017.

WEISMAN, C. Inside the world of 'macrophilia'. AlterNet - Sex \& Relationships, 2014.

WONG, K. We spoke to a sex therapist about the Tall Lady in 'Resident Evil Village'. Complex - Pop Culture, 2021.

WYSOCKI, M.; LAUTERIA, E. Rated M for Mature: Sex and Sexuality in Video Games. New York: Bloomsbury, 2016.

YIN-POOLE, W. Capcom made a life-sized towel of Lady Dimitrescu. Eurogamer - Hightlights, 2021.

YIN, R. K. Estudo de Caso. $2^{\mathrm{a}}$ ed. Bookman: Rio de Janeiro, 2001. 